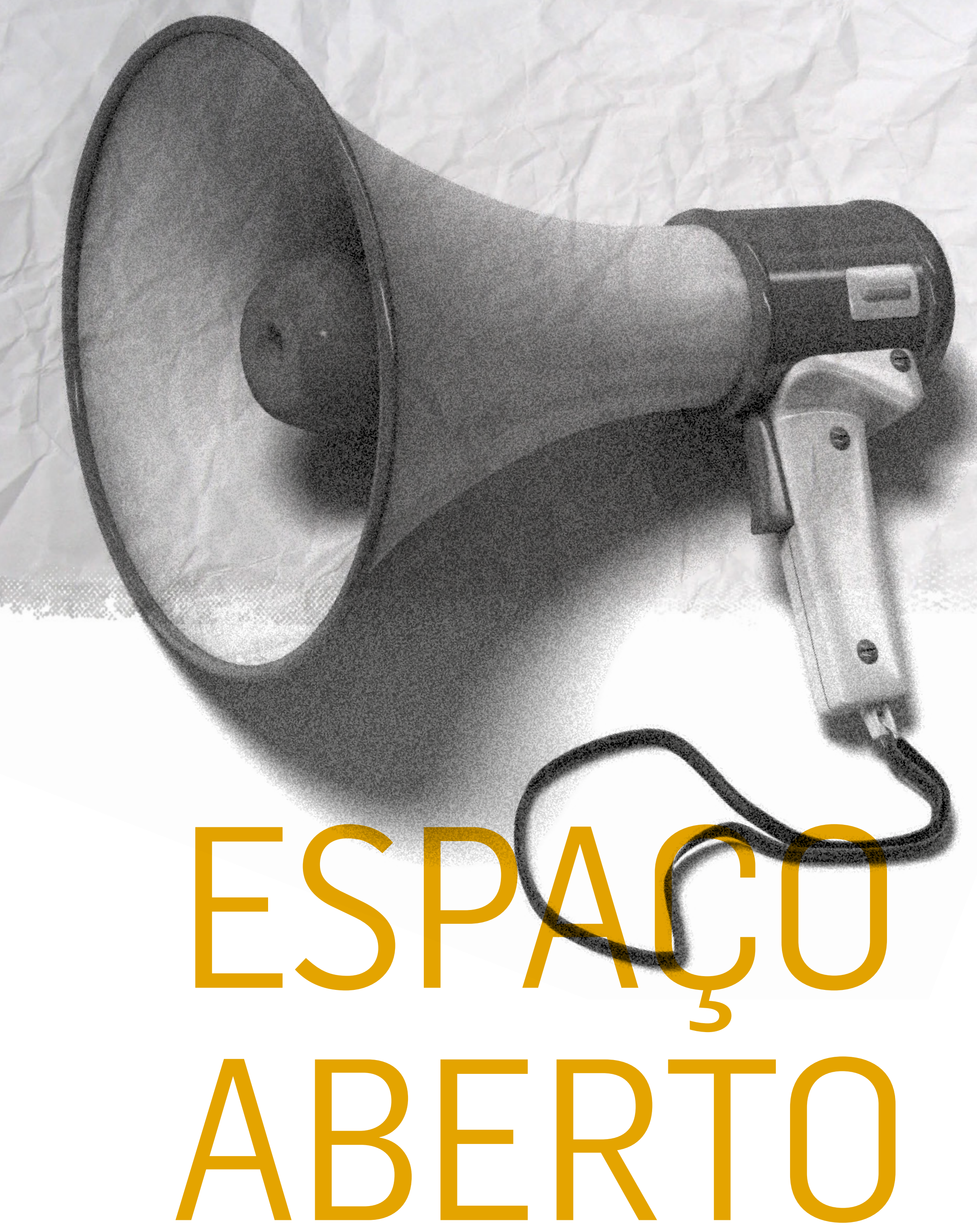




\section{Crise ambiental e crise de informação: reflexões sobre a opinião pública no contexto da sustentabilidade}

Environmental crisis and information crisis: reflections on public opinion in the context of sustainability

Crisis ambiental y crisis de la información: reflexiones sobre la opinión pública en el contexto de la sostenibilidad

Giovanna Migotto da Fonseca Galleli

- Mestre em Gestão de Organizações, pelo Programa de Pós-Graduação em Administração da Universidade Estadual de Londrina (UEL)

- Especialista em Administração de Marketing e Propaganda pela Uel e em Gestão Empresarial pela Fundação Getúlio Vargas (FGV)

- Graduada em em Relações Públicas pela UEL

- Trabalha na Companhia de Saneamento do Paraná (Sanepar) como assessora de Comunicação e Imprensa há 16 anos

- E-mail: gigigalleli@gmail.com

\section{Milene Rocha Lourenço Leitzke}

- Mestre em Gestão de Organizações, pelo Programa de Pós-Graduação em Administração da Universidade Estadual de Londrina (UEL)

- $\quad$ Especialista em Assessoria de Comunicação pela Faculdade Pitágoras

- Graduada em Relações Públicas pela UEL

- Professora na Universidade Norte do Paraná (Unopar) e no Centro Universitário Anhanguera, de Londrina

- E-mail: milene.rrpp@gmail.com 


\section{Resumo}

O objetivo deste ensaio é promover reflexões a respeito do comportamento da opinião pública sobre a crise ambiental, que se encontra no centro do debate sobre a sustentabilidade. Parte-se da premissa de que há uma crise de informação na crise ambiental, desvelando, por um lado, uma visão da sustentabilidade como estratégia de mercado, embasada nos discursos sustentáveis em busca de lucro e ganho de imagem, e, de outro, um clima de desconfiança quanto à real dimensão dos riscos que envolvem a exploração dos recursos naturais. Após revisão de literatura, chega-se ao entendimento de que 0 contexto da sustentabilidade se encontra permeado de "não-atitudes", opiniões artificiais, instáveis e vazias de conteúdos.

\section{PALAVRAS-CHAVE: CRISE DE INFORMAÇÃO・CRISE AMBIENTAL・SUSTENTABILIDADE・OPINIÃO PÚBLICA.}

\section{Abstract}

The purpose of this essay is to promote reflections on the behavior of public opinion concerning the environmental crisis, which is at the heart of the sustainability debate. It is based on the premise that there is an information crisis in the environmental crisis, revealing, on the one hand, a vision of sustainability as a market strategy, based on sustainable discourses for profit and image gain, and, on the other hand, distrust over the real dimension of the risks involving the exploitation of natural resources. After reviewing the literature, one comes at the understanding that the context of sustainability is permeated by "non-attitudes", artificial, unstable and empty-of-content opinions.

\section{KEYWORDS: CRISIS INFORMATION・ENVIRONMENTAL CRISIS・SUSTAINABILITY・PUBLIC OPINION.}

\section{Resumen}

El objetivo de este ensayo es promover reflexiones al respecto del comportamiento de la opinión pública sobre la crisis ambiental, que se encuentra en el centro del debate sobre las sustentabilidad. Se parte de la premisa de que hay una crisis de información en la crisis ambiental, descubriendo, por un lado, una visión de sustentabilidad como estrategia de mercado, basada a los discursos sustentables en busca de lucro y buena imagen, y, por otro lado, un clima de desconfianza con relación a la dimensión real de los riesgos que envuelven la explotación de los recursos naturales. Después de la revisión de la literatura, se llega a un entendimiento de que el contexto de la sustentabilidad se encuentra permeado de "no actitudes", opiniones artificiales, inestables y vacías de contenido. 
A fim de discutir a formação da opinião pública no contexto da sustentabilidade, onde coexistem o comércio de riscos ambientais e os discursos das organizações, este ensaio parte da prerrogativa de que há uma crise de informação na crise ambiental. Para isto, contextualiza as discussões diante das constantes mudanças que a sociedade tem enfrentado em decorrência da globalização, das inovações tecnológicas, do aumento da diversidade cultural e das preocupações com questões éticas, entre outros fatores. Nesse cenário, se torna evidente o apelo dos sujeitos em defesa do meio ambiente.

Autores como Boaventura de Souza Santos (2009) e Ulrich Beck (2010) acreditam que esse contexto é resultado de um momento transitório, em que as propostas oferecidas com o advento da modernidade acabaram, em alguns casos, voltandose contra a própria sociedade. Um exemplo são as usinas nucleares que, construídas com o suporte da ciência e da tecnologia - pilares que sustentaram todo período moderno -, desencadearam um período de medo e insegurança, pois oferecem ameaças iminentes à população. Os pilares da modernidade já não são capazes de superar os riscos que ocasionaram. Vivese, portanto, uma crise da modernidade (SANTOS, 2009, BECK, 2010; GIDDENS, 1991).

Dessa forma, nota-se que essa realidade tem trazido, para o ambiente organizacional, desafios diários quanto ao desenvolvimento de ações que contemplem o cuidado com o meio ambiente e com os sujeitos que compõem a comunidade. Acredita-se, com isso, que é preciso agir e comunicar o que está sendo feito diante da poluição atmosférica, do aquecimento global, da desigualdade social, entre outros aspectos que configuram a crise ambiental.

Defende-se neste ensaio a concepção da sustentabilidade como valor para as organizações (BALDISSERA, 2009), porém, notadamente, é cada vez mais estratégico para as organizações transmitir a imagem de socialmente responsáveis e ambientalmente corretas, visando obter maior confiança dos públicos e agregar valor à sua reputação. Assim, entre outros aspectos, a sustentabilidade se tornou uma estratégia de mercado ou modismo.

Sendo assim, as informações presentes nos discursos sustentáveis nem sempre correspondem à realidade. Por causa disso, o título de empresa responsável torna as organizações dependentes das práticas sustentáveis, principalmente para obtenção de lucro e sucesso (BARBOSA, 2013).

Nesse mesmo cenário, Beck (2010) denuncia disputas definitórias entre a sociedade da ciência, da mídia e da informação em torno da extensão, do grau e da urgência dos riscos ambientais, situação na qual especialistas têm o papel e 0 poder de diferenciar aspectos que geram medo e aspectos que transmitem segurança. As opiniões são formadas em um contexto no qual, para o autor, existe falsidade da informação no prognóstico e na comercialização dos riscos, cercada de erros, fraudes, equívocos e verdades.

Dessa maneira, há uma preocupação em compreender como a opinião pública recebe o discurso das organizações no contexto da sustentabilidade e como ela se comporta nessa realidade. Para tanto, parte-se do entendimento de que opinião pública envolve "um processo de discussão coletiva e que se refira a um tema de relevância pública (ainda que não diga respeito a toda a sociedade), esteja sendo expresso publicamente, seja por sujeitos individuais em situações diversas, seja em manifestações coletivas" (FIGUEIREDO; CERVILLINI, 1995, p. 178).

Assim, o presente ensaio busca promover reflexões a respeito do comportamento das organizações e da opinião pública, em relação à crise ambiental, a qual se encontra no centro de todo o debate sobre sustentabilidade. As discussões presentes neste trabalho discorrem sobre a geração de conhecimento e a formação da opinião diante da falta de credibilidade dos 
pilares da modernidade e da infinidade de fontes e interesses ocultos presentes na disseminação de informação. Considerase, ainda, a falta de consenso quanto ao significado dos termos desenvolvimento sustentável e sustentabilidade.

Desse modo, 0 artigo apresenta argumentos a respeito do status da crise ambiental e da sustentabilidade na contemporaneidade e, em seguida, sobre a crise de informação e seu impacto na opinião pública. Essas discussões oferecem suporte para a compreensão do contexto da sustentabilidade, o qual se encontra permeado de "não-atitudes", segundo Philip E. Converse (1964, apud FIGUEIREDO e CERVILLINI, 1995, p. 181), de opiniões artificiais, instáveis e vazias e não como um valor, como defendemos.

\section{A CRISE AMBIENTAL E A SUSTENTABILIDADE NA CONTEMPORANEIDADE}

Vive-se um momento de transição da modernidade (SANTOS, 2009; BECK, 2010), marcado por questionamentos às grandes instituições, que se formaram no Século XVIII, e pela perda de confiança e de credibilidade em relação à ciência, tecnologia e informação, em consequência de promessas não compridas e dos efeitos nocivos de suas ações.

A modernidade, que surgiu com a proposta de anular as limitações impostas pelo nascimento e propiciar às pessoas uma posição na estrutura social em razão de suas próprias escolhas e seus esforços (BECK, 2010), atualmente se encontra em meio às premissas e aos princípios socioindustriais. Tal situação demonstra a crise, a qual Beck (2010) denomina crise da modernidade e que está intrinsecamente ligada às relações estabelecidas entre os seres humanos e a natureza. Observase, então, uma estreita aproximação com o incentivo exacerbado do consumismo, o que leva as organizações a extraírem recursos do meio ambiente de maneira ilimitada, gerando uma série de impactos ambientais de abrangência global.

Por isso, Beck (2010) afirma que a humanidade caminha rumo a uma outra modernidade, à modernidade reflexiva, marcada por uma sociedade que, muitas vezes, tem o risco como fonte de sobrevivência. 0 autor observa que, para algumas organizações, o risco é um negócio que pode, em alguns casos, colocar a sociedade em situações de vulnerabilidade. Dessa maneira, na sociedade de risco, como Beck (2010) caracteriza a sociedade atual, a produção de risco acompanha a produção de riqueza e, por isso, se faz presente em todos os locais, atingindo toda a população, sem distinção de classe social.

Nesse sentido, pode-se dizer que a crise ambiental se configura como um reflexo da crise da modernidade, que resulta em uma sociedade de instabilidade e imprecisão, na qual o ambiente sofre ameaças e ameaça os sujeitos que o habita. 0 consumismo exagerado, a grande extração de recursos naturais, a desigualdade social, a marginalização e a pobreza são exemplos desse cenário.

Diante disso, Guillermo Foladori (2001) argumenta que a realidade se repete, mesmo após a tomada de consciência sobre a crise ambiental na década de 1960 e a percepção da mudança em escala planetária entre 1970 e 1980. Ele acredita que esses marcos históricos não deixaram "claro por que razões o ser humano levou o equilíbrio ecológico a um nível tão delicado para a sua própria sobrevivência e possivelmente para a de muitas outras espécies" (FOLADORI, 2001, p. 15).

Por conseguinte, os esforços de entidades como organizações não-governamentais (ONGs) e grupos de defesa ao meio ambiente, para conscientizar a população, são contínuos. No entanto, é a partir da década de 1980, diante do fraco desempenho econômico em que a sociedade se encontrava, em vista da necessidade de reorganizar a ordem social para ambientalmente mais correta, que se dá início à discussão mais intensa sobre a crise ambiental. 
A crítica aos padrões de crescimento e desenvolvimento ganhou força, principalmente, com a publicação do Relatório de Brundtland, pela Comissão Mundial sobre Meio Ambiente (WCED), em 1987, que trouxe um olhar sobre as gerações futuras e envolveu lideranças de diferentes países. 0 documento trata do desenvolvimento sustentável como aquele que satisfaz as necessidades do presente sem comprometer a capacidade das gerações futuras de satisfazerem suas próprias necessidades. Embora considerada ambígua e simplista (CLARO, CLARO e AMÂNCIO, 2008; REDCLIF, 2006; BARONI, 1992; MUNCK, 2013), essa definição passou a ser mainstream nas comunidades científica, acadêmica, política e empresarial.

Desse modo, nota-se que a ideia de desenvolvimento sustentável passou a ser associada a práticas e políticas de maneira acrítica, para beneficiar marcas (REDCLIF, 2006), especialmente depois da Conferência das Nações Unidas sobre 0 Meio Ambiente e o Desenvolvimento (Cnumad), conhecida também como ECO-92, Rio-92. Nesse cenário, empresas têm demonstrado dificuldade em associar seus discursos e suas práticas gerenciais a uma definição completa de sustentabilidade (CLARO; CLARO; AMÂNCIO, 2008).

Mesmo diante de um contexto que apresenta preocupação com o meio ambiente e com as gerações futuras, nota-se que grande parte dos esforços em prol do desenvolvimento sustentável estáligada às questões econômicas. Conquanto se defenda o equilíbrio das dimensões social, ambiental, territorial, política e econômica (SACHS, 2008), tem-se a percepção de que a maioria das ações em prol do desenvolvimento sustentável no mundo dos negócios visa desenvolver a capacidade financeira das empresas.

Percebe-se, assim, queasindústrias não param, aumentam a produção de maneira incontrolável, o que,consequentemente agrava, cada vez mais, os impactos ambientais, com a extração ilimitada dos recursos naturais e a poluição do planeta. A busca desenfreada pelo lucro faz com que as organizações empreendam discursos sustentáveis somente com a finalidade de obter vantagem competitiva. Assim, torna-se evidente que muitas empresas ainda não desenvolveram qualquer estratégia coerente com seu discurso (MUNCK, 2013).

Por essa razão, autores como Carlos J. Castro (2004) e Marcionila Fernandes (2003) entendem que a expressão desenvolvimento sustentável tem se tornado sinônimo de desenvolvimento econômico, centrado na racionalidade econômica, que visa ao progresso do capital às custas do controle e monitoramento dos recursos naturais.

Compartilhando de mesmo entendimento, Bueno (2012) critica a concepção equivocada de desenvolvimento sustentável como crescimento econômico, mensurado em indicadores econômicos, como o PIB (produto interno bruto), que não traduzem o respeito ao meio ambiente e aos direitos humanos. Esse autor chama a atenção para discursos verdes, diante de um esvaziamento conceitual e da não-incorporação do que está na origem do desenvolvimento sustentável ao processo de gestão das organizações. Dessa maneira, ele também acredita que o discurso da sustentabilidade tem sido utilizado para legitimar posturas e ações nem sempre adequadas ou éticas, com o objetivo de gerar imagem positiva.

\section{A CRISE DA INFORMAÇÃO E O IMPACTO NA OPINIÃO PÚBLICA}

A sustentabilidade é o pano de fundo para a crítica quanto aos discursos das organizações, bem como sobre a disseminação de informações, muitas vezes enviesadas, a respeito das dimensões da crise ambiental. 0 contexto é 0 da articulação de multimeios, porém, com o conteúdo podendo revelar-se de caráter tendencioso, como acusa Beck. Ele diz que o poder de quem pode anunciar "do que se deve ter medo e do que não" (BECK, 2010, p. 64) proporciona o entendimento sobre o grau de ameaça, sempre na dependência do conhecimento alheio, dos intitulados especialistas e de informações muitas vezes parciais. 
Assim, para além da questão ambiental, pode-se estender a crise para a dimensão da informação, o que, para Beck (2010), aumenta a importância social e política do conhecimento e, consequentemente, do acesso aos meios de forjá-lo (ciência e pesquisa) e disseminá-lo (meios de comunicação de massa). Dessa maneira, ao comentar sobre a sociedade de risco, o autor denuncia a falsidade da informação no prognóstico e na comercialização dos riscos, cercada de erros, fraudes, equívocos e verdades, diante de uma população considerada ignorante, que sofre danos à sua saúde, enquanto os cientistas têm apenas suas reputações arranhadas.

Para Beck (2010), os cientistas colocam-se como juízes da "irracionalidade" da população, em um contexto no qual a consciência dos riscos é determinada e orientada cientificamente, podendo haver um processo de conscientização reversível, com a negação promovida pelo medo, pois "protestos, temores, crítica e resistência no espaço público são todos um mero problema de informação" (BECK, 2010, p. 69, grifo do autor).

Baldissera (2009, p. 34) também observa que "cientistas de todas as partes do mundo apresentam estudos que evidenciam o esgotamento dos recursos naturais e, particularmente, o desiquilíbrio ecossistêmico que põe em xeque a própria continuidade da vida". Beck (2010, p. 56) afirma que não se sabe "se todo o discurso em torno do risco não é expressão de uma dramaturgia política deslocada, que pretende, na verdade, algo inteiramente distinto". Quanto a isso, o autor defende a educação e uma postura sensível à informação, que deve contextualizar histórica e socialmente os riscos globais.

Seguindo, Beck (2010) indica que os riscos se tornaram oportunidades de mercado, fortalecendo a oposição entre os que são afetados e aqueles que lucram com eles, alterando a lógica da distribuição de riqueza na sociedade da escassez para a lógica da distribuição de riscos na modernidade tardia. Em um contexto, segundo o autor, de interesses conflitivos e de diversidade de interpretações sobre os riscos, é preciso promover a conscientização para uma mudança efetiva em prol da sustentabilidade.

Complementando esse raciocínio, vale salientar a visão de Baldissera (2009) a respeito dos vários sentidos atribuidos à sustentabilidade, pois, em um deles, o autor destaca a questão da sustentabildiade como valor periférico e/ou estratégico de mercado. Para ele, essa visão da sustentabilidade, como já foi citado, tem sido o mais valorizado, principalmente pelas grandes corporações.

0 esforço de Baldissera (2009, p. 49) na categorização dos sentidos e da aplicação da ideia de sustentabilidade permite reflexões sobre o que ele próprio chama de "engodos, contradições, fertilidades, ignorância, expropriação, mistificações, explorações etc.", coincidindo com o entendimento de Beck (2010).

Cabe, portanto, chamar a atenção para os impactos dessa crise de informação sobre a opinião pública e para como esta compreende as ações das organizações nesse contexto. Podem-se revelar sentimentos de desconfiança e incerteza em relação aos discursos sustentáveis, provocando, por conseguinte, opiniões vazias de conteúdo e ação.

Isso pode estar acontecendo, muitas vezes, porque o processo de formação da opinião pública envolve fatores de caráter racional e emocional, que não está limitado a assuntos públicos e, especialmente, não está relacionado unicamente às "opiniões comuns" mensuradas em pesquisas, sendo estas apenas uma das formas de deliberação e de troca (FIGUEIREDO; CERVELLINI, 1995, p. 181). 
Portanto, essa afirmação permite inferir que o contexto da sustentabilidade é permeado da existência de um fenômeno chamado "não-atitudes", conforme a tese de Philip Converse (1964, apud FIGUEIREDO; CERVILLINI, 1995, p. 181), que defende que o citado fenômeno pode ser traduzido em opiniões artificiais e instáveis, vazias de conteúdo, bem como com ausência de atitude real.

Por esse motivo, a crítica de Pierre Bourdieu (1973, p. 4), ao levantamento da opinião pública por meio de pesquisa, fazse importante, já que ele destaca que a opinião pública não é a soma pura e simples de opiniões individuais e, sim, de conflitos de força entre os grupos e as forças mobilizadas. Para ele, pesquisas buscam "legitimar uma política e reforçar as relações de força que a fundamentam ou a tornam possível", ou seja, forjar um consenso. Além disso, para Bourdieu (1973), há problemas morais e éticos sobre os quais as pessoas não se perguntaram, justamente como é possível ver no contexto da sustentabilidade que foi descrito até aqui.

Nesse sentido, vislumbra-se a necessidade de uma mudança cultural, com base no entendimento de Figueiredo e Cervillini (1995, p. 182) que afirmam que, para que um fenômeno de opinião pública passe de latente para ativo, existe a dependência "da relevância e do nível de relação que o estímulo ativador mantém com os valores, crenças e atitudes básicos do indivíduo".

Diante do exposto, chega-se ao ponto de que a falta ou excesso de informação, os vieses e os jogos de interesses por trás das informações podem estar contribuindo para essa limitada percepção da sustentabilidade e da necessidade de mudanças culturais e de paradigma.

\section{REFLEXÕES}

0 entendimento de que vivemos em uma sociedade complexa e estamos passando por um momento transitório guia as discussões deste ensaio, uma vez que se vive em um mundo cada vez mais pluralista e interdependente, marcado por um novo contexto social, econômico e ambiental, defendido a partir das premissas da sustentabilidade.

Por esse motivo, Stanley Deetz (2009) acredita que é preciso construir um novo modo de ver o mundo, a partir de conceitos de colaboração, de direitos das comunidades e de liberdades e adquirir práticas de comunicação diferentes, o que, no entendimento deste estudo, encontra lugar na sustentabilidade como valor central na sociedade, conforme defende Baldissera (2009).

É no contexto da sustentabilidade, portanto, que se centra a precupação com a postura das organizações, cobradas pela sociedade, que exige que elas sejam ambientalmente corretas e socialmente responsáveis. Acontece que muitas delas adotam medidas sustentáveis que não são cumpridas ou que não fazem parte do plano estratégico de suas ações (MUNCK, 2013).

Assim, muito do que é proposto pelas organizações permanece apenas no discurso, que lhes garante credibilidade perante seus públicos. Além disso, as empresas que colocam em prática ações sustentáveis visam, prioritariamente, à questão econômica.

Na questão ambiental, é possivel observar algumas ações organizacionais. Entretanto, estas tornam-se pequenas quando comparadas aos danos que as organizações causam ao meio ambiente, como a emissão de gases tóxicos, o despejo irregular de resíduos e efluentes em rios, entre outros. Beck (2010), como já citado no ensaio, denuncia os impactos das organizações sobre o meio ambiente, ponderando a respeito dos riscos provocados por elas e a relação de sobrevivência que se estabeleceu. Segundo o autor, muitas organizações dependem do risco para gerar lucro. 
Diante disso, questiona-se: como essas organizações podem ser consideradas sustentáveis e colaborar para o melhoramento da crise ambiental? Como organizações que têm suas atividades ligadas aos riscos que atingem os seres humanos podem ser consideradas socialmente responsáveis? Como essas organizações conseguem o apoio da sociedade para manter suas atividades, uma vez que os riscos produzidos são nocivos à sobrevivência do planeta?

Frente a esses questionamentos, utiliza-se a visão de Beck (2010) para um respaldo a essas indagações, pois para o autor, não obstante as organizações produzirem os riscos e ameaçarem a vida na terra, suas ações são justificadas pelos argumentos em prol da qualidade de vida e do aumento da riqueza da população. Contudo, observa-se que a maior parte da riqueza produzida em torno da produção dos riscos concentra-se nas mãos de apenas $20 \%$ da população do planeta, assim como referem Mark Hathaway e Leonardo Boff (2012).

Ainda citando Beck (2010), nota-se que o conformismo da sociedade e o apoio, muitas vezes, às atividades industriais nocivas é resultado de uma política de informações manipuladas pelos veículos de comunicação, bem como, pelas afirmações embasadas na ciência e na tecnologia.

Ainda que se perceba uma crescente mudança em relação à confiança a respeito dos pilares da modernidade - ciência, tecnologia e informação -, esses ainda possuem força sobre a opinião das pessoas, o que faz, muitas vezes, que as informações sejam distorcidas, com a finalidade de atender a interesses específicos. Tal situação é observada por Howlett (2000, p. 68), que versa sobre a existência de ferramentas para a criação e manipulação de grupos de interesse, sendo que "tais instrumentos procedimentais 'negativos' incluem a supressão de informações, e o fingimento, ofuscação e outras formas de adiamento administrativo".

Com isso, parece ainda mais evidente a crise de informação sobre a crise ambiental. Então, propõe-se refletir sobre outras questões, tais como: é possivel confiar nas informações contidas nos discursos das organizações, muitas vezes amparadas pela ciência? Como saber se o que está sendo informado atende grupos de interesses e não objetiva nenhum tipo de contribuição para a população? Como a opinião pública deveria agir em relação a esses pontos?

Há um entendimento de que o estudo traz um desafio complexo, uma vez que, dentro da própria opinião pública, formada em determinado assunto, existem divergências de valores e opiniões, pois não se trata de uma opinião unânime nem de uma opinião predominante (FORTES, 2003). Torna-se ousado julgar as atitudes e a postura das organizações diante daquilo que é informado por elas e diante do comércio dos riscos.

Veicula-se, ainda, que, fora do ambiente acadêmico-científico, para a população em geral, a crise ambiental vem sendo revelada pela mídia, a partir de iniciativas de organizações não-governamentais e de campanhas que reúnem ativistas anônimos efamosos, bem como pela publicidade de projetos sustentáveis feita por várias empresas. De maneira ampla, é possível afirmar igualmente que a informação acerca das dimensões da crise ambiental, especialmente no que diz respeito às condições climáticas do planeta, ganhou o mundo por meio de séries televisivas, bem como pelo documentário Uma verdade inconveniente, proposto pelo político e ecologista norte-americano Al Gore, em 2006. Mesmo aqueles que não assistiram às imagens do documentário, tomaram conhecimento do seu conteúdo na repercussão dada pelos meios de comunicação de massa.

Notícias como essas são reveladas sobre as ações das grandes organizações a todo momento. As novas tecnologias permitem o acesso a informações que muitas vezes são confidenciais e ou, até mesmo, forjadas. 0 contato com essas informações gera um embate em relação ao discurso propagado e coloca, com isso, a opinião pública em situação delicada, já que se 
passa a não mais acreditar nas informações recebidas das organizações. Gera-se, a partir de então, um processo de perda de confiança e de credibilidade, que, por sua vez, pode destruir a reputação de uma organização.

Por fim, este ensaio não pretende responder a esses questionamentos, mas despertar o interesse para reflexões sobre 0 assunto e destacar a importância de entender o processo pelo qual a informação e a opinião pública se formam e, ao mesmo tempo, constroem o contexto atual. Perante esse cenário, vê-se a importância de uma comunicação na constituição de um discurso social para uma mudança efetiva de estilos de vida, em que a responsabilidade pela sustentabilidade do planeta deve ser compartilhada no que se refere a novos valores quanto ao bom uso da economia e da ecologia.

\section{CONSIDERAÇÕES FINAIS}

Diante das questões apresentadas, presentes em um contexto compartimentado e multifacetado, é possível concluir que a discussão sobre a sustentabilidade está polarizada e não é consensual; que se caminha de um processo latente para o ativo, perante a opinião pública, permanecendo, porém, a distância entre os discursos e as práticas das organizações. Isso com base na diversidade de opiniões manifestadas por especialistas/cientistas, empresários, membros de ONGs e população em geral (interessados e não-interessados) diante de ações que buscam, na verdade, legitimar uma ética particular que visa predominantemente, ou mesmo exclusivamente, garantir a sustentabilidade dos negócios (BUENO, 2009).

De todo modo, nota-se que a sustentabilidade é um tema de grande relevância e de interesse mundial, mas de difícil entendimento, pela falta de consenso conceitual, bem como pela crise de informação que delimita o seu contexto.

Acredita-se, portanto, na relevância deste ensaio, por chamar a atenção para o novo contexto sócio-histórico e cultural no qual a sustentabilidade e a crise ambiental figuram como temas polêmicos, foco de interessantes discussões, um contexto de disputas definitórias e de comércio de informações. O contexto é complexo e controverso, no qual as organizações precisam comunicar-se com seus públicos, ganhar confiança, fidelizar, situações em que é preciso empenhar-se para mostrar se age de fato em favor da sustentabilidade e não somente com palavras e discurso. É importante dizer, por fim, que se defende uma mudança que promova a sustentabilidade como um valor central na sociedade e no core business.

\section{REFERÊNCIAS}

BALDISSERA, Rudimar. A comunicação (re)tecendo a cultura da sustentabilidade na construção de uma nova visão de mundo. In: KUNSCH, Margaria M. Krohling; OLIVEIRA, Ivone de Lourdes (Orgs.). A comunicação na gestão da sustentabilidade das organizações. São Caetano do Sul, SP: Difusão Editora, 2009. p. 33-55.

BARBOSA, Mariana, P. A comunicação como ferramenta de prevenção e controle em situações de risco. In: ENCONTRO INTERDISCIPLINAR DE COMUNICAÇÃO AMBIENTAL - EICA, 2º, Universidade Federal de Sergipe, maio de 2013. Anais... Aracaju: UFS, 2013.

BARONI, Margaret. Ambiguidades e deficiências do conceito de desenvolvimento sustentável. Revista de Administração de Empresas, São Paulo, v. 32, n. 2: 14-24, abr./jun. 1992. 
BOURDIEU, Pierre. A opinião pública não existe. Les Temps Modernes, n. 318, janeiro de 1973.

BUENO, Wilson da Costa. Comunicação, iniciativa privada e interesse público. In: DUARTE, Jorge (Org.). Comunicação pública: estado, mercado, sociedade e interesse público. 2. Ed. São Paulo: Atlas, 2009. P.- 134-153.

Comunicação e sustentabilidade: aproximações e rupturas. Razón y Palabra, n. 79, mayo-julio, 2012.

CASTRO, Carlos J. Sustainable development: mainstream and critical perspectives. Organization \& Environment, v. 17, n. 2, p. 195-225, jun. 2004.

CLARO, Priscila de Oliveira; CLARO, Danny Pimentel; AMÂNCIO, Robson. Entendendo o conceito de sustentabilidade nas organizações. Revista de Administração da Universidade de São Paulo, São Paulo, v. 43, n. 4, p.289-300, out./nov./dez. 2008.

DEETZ, Stanley. A ascensão dos modelos de governança dos stakeholders e o consequente redesenho da comunicação. In: KUNSCH, Margaria M. Krohling; OLIVEIRA, Ivone de Lourdes (Orgs.). A comunicação na gestão da sustentabilidade das organizações. São Caetano do Sul, SP: Difusão Editora, 2009. p. 85-105.

FERNANDES, Marcionila. Desenvolvimento sustentável: antinomias de um conceito. In: FERNANDES, Marcionila; GUERRA, Leonel. Contra-discurso do desenvolvimento sustentável. Belém: Associação de Universidades Amazônicas, 2003.

FIGUEIREDO, Rubens; CERVELLINI, Sílvia. Contribuições para o conceito de opinião pública. Opinião Pública, Campinas, v. III, n. 3, dez. 1995. p.171-185,

FOLADORI, Guillermo. Limites do desenvolvimento sustentável. Campinas, SP: Editora da Unicamp; São Paulo: Imprensa Oficial, 2001.

FORTES, Waldyr Gutierrez. Relações públicas: processos, funções, tecnologia e estratégias. 2. ed. São Paulo: Summus, 2003.

HATHAWAY, Mark; BOFF, Leonardo. O tao da libertação: explorando a ecologia da transformação. Petrópolis, RJ: Vozes, 2012.

GIDDENS, Anthony. As consequências da modernidade/Anthony Giddens. Trad. de Raul Fiker. São Paulo: Editora Unesp, 1991.

HOWLETT, Michael. A dialética da opinião pública: efeitos recíprocos da política pública e da opinião pública em sociedades democráticas contemporâneas. Opinião Pública, Campinas, v. VI, n. 2, p. 167-186,2000.

MUNCK, Luciano. Gestão da sustentabilidade nas organizações: um novo agir frente à lógica das competências. São Paulo: Cengage Learning, 2013.

REDCLIF, Michael R. Sustainable development (1987-2005): an oxymoron comes of age. Horizontes Antropológicos, Porto Alegre, a. 12, n. 25, p. 65-84, jan./jun. 2006.

SACHS, Ignacy. Desenvolvimento: includente, sustentável e sustentado. Rio de Janeiro: Garamond, 2008.

SANTOS, Boaventura de Sousa. A crítica da razão indolente: contra o desperdício da experiência. 7. ed. São Paulo: Cortez, 2009.

Artigo recebido em 23.08.2016 e aprovado em 14.10.2016. 